\title{
Optimasi Formula Sediaan Krim Sunflower (Helianthus annuus L.) Oil
}

\section{(Formula Optimation of Sunflower (Helianthus annuus L.) Oil Cream Formula)}

\author{
EVA HUSEIN, AGATHA BUDI SUSIANA LESTARI*
}

Fakultas Farmasi Universitas Sanata Dharma

Kampus III, Paingan, Maguwoharjo, Depok, Sleman, Yogyakarta.

Diterima 2 Januari 2018, Disetujui 22 Maret 2019

\begin{abstract}
Abstrak: Minyak biji bunga matahari (sunflower oil) banyak digunakan dalam krim pelembap untuk menjaga kehalusan dan kelembapan kulit. Penggunaan emulgator yang tepat dapat membantu terbentuknya sediaan krim yang stabil. Penelitian ini bertujuan untuk mencari komposisi optimum antara Tween 80 dan Span 80 yang menghasilkan sediaan krim dengan sifat fisik dan stabilitas fisik yang baik ditinjau dari viskositas, daya sebar, dan pergeseran viskositas setelah 30 hari. Kemampuan krim dalam mempertahankan kelembapan kulit diuji dengan metode Transepidermal Water Loss (TEWL). Rancangan penelitian menggunakan Simplex Lattice Design 2 faktor 2 level. Hasil penelitian menunjukkan bahwa dari formula yang diuji, terdapat 3 formula yang memenuhi persyaratan untuk respon yang diuji, yaitu pada kombinasi Tween 80:Span $80(6: 4) \%$, (7:3)\%, dan (8:2)\%. Viskositas yang diperoleh berada dalam kisaran 143,3-153,3 dPas, daya sebar antara 5,0-5,3 cm, dan pergeseran viskositas antara 4,3-6,8\%. Uji TEWL dilakukan terhadap formula optimum yang diperoleh, dan penurunan TEWL yang diperoleh berkisar antara 17,9-38,0\%. Berdasarkan data yang diperoleh, dapat disimpulkan bahwa sunflower oil dapat diformulasikan dalam sediaan krim menggunakan kombinasi Tween 80 dan Span 80 pada konsentrasi $(6: 4) \%$, (7:3)\%, dan $(8: 2) \%$ yang memenuhi persyaratan viskositas, daya sebar, dan pergeseran viskositas selama waktu penyimpanan 30 hari, dan terbukti mampu mempertahankan kelembapan kulit.
\end{abstract}

Kata kunci: Sunflower oil, krim, tween 80, span 80, simplex lattice design.

\begin{abstract}
Sunflower oil is one of the components of moisturizing cream that keeps the moisture of the skin. To produce a good quality cream, it is necessary to select appropriate emulsifying agent. This study aims to find the optimum composition between Tween 80 and Span 80 as an emulsifying agent in the preparation of sunflower oil cream, to meet physical properties and physical stability in terms of viscosity, spread ability and viscosity shift for 30 days. The ability of the cream to maintain skin moisture was tested using the Transepidermal Water Loss (TEWL) method. This study used a 22 experimental research design with the Simplex Lattice Design. The results showed there are 3 formulas of Tween 80 and Span 80 in proportion $(6: 4) \%,(7 ; 3) \%$ and $(8: 2) \%$ that fulfill the requirements with $143,3-153,3$ dPas in viscosity, spread ability in range 5,0-5,3 cm, and viscosity shift between 4,3-6,8\%. Based on TEWL test, the optimum formula obtained has a moisturizing effect with a TEWL value 17,9$38,0 \%$. It conclude, sunflower oil could be formulated into moisturizing cream using combination of Tween 80 and Span 80 in proportion $(6: 4) \%,(7 ; 3) \%$ and $(8: 2) \%$ to fulfill the requirements for 30 days and could keep the skin moisture.
\end{abstract}

Keywords: Sunflower oil, cream, tween 80, span 80, simplex lattice design. 


\section{PENDAHULUAN}

DALAM cuaca panas, paparan terhadap pendingin udara (AC) memang menyejukkan, namun jika terlalu lama dapat memicu hilangnya kelembapan kulit yang akhirnya menyebabkan kulit menjadi kering. Kulit yang kering sangat tidak nyaman, terasa kaku, dan mudah bersisik. Dalam hal ini, elemen alami kulit yang disebut dengan natural moisturizing factors (NMF) tidak lagi dapat menjaga kelembaban kulit dengan baik. Oleh karena itu, banyak orang yang memakai krim pelembap atau moisturizer untuk menjaga agar kulit tetap terlindungi dan terhidrasi dengan baik.

Salah satu bahan yang banyak digunakan dalam sediaan krim pelembap adalah sunflower oil, karena banyak mengandung vitamin E dan essential fatty acids (EFA) seperti asam linoleat, asam oleat, asam palmitat, dan asam stearat(1). Asam linoleat merupakan salah satu contoh lipid NMF yang terdapat di kulit yang berfungsi dalam menjaga hidrasi kulit, dengan demikian sunflower oil dapat menggantikan NMF dalam mempertahankan kelembapan kulit(2).

Pemilihan emulgator menjadi pertimbangan penting dalam pembuatan sediaan krim karena akan berperan dalam pembentukan emulsi yang baik dan sediaan krim yang stabil. Untuk mendapatkan emulgator yang dapat memberikan nilai hydrophiliclipophilic balance (HLB) yang sesuai dengan tujuan pembuatan krim, biasanya digunakan emulgator dalam bentuk kombinasi, misalnya kombinasi antara polysorbate dan sorbitan esters umum digunakan bersamaan(3)

Dalam penelitian ini digunakan kombinasi antara Tween 80 dan Span 80 . Tween 80 adalah emulsifying agent larut air dan Span 80 adalah emulsifying agent nonionik yang gugus lipofilnya lebih dominan sehingga kombinasi kedua surfaktan tersebut mampu mempengaruhi nilai HLB dari masing-masing surfaktan secara tunggal pada perbandingan tertentu dan dapat mencapai rentang nilai HLB krim M/A yang diinginkan yaitu $8-13^{(4)}$. Selain itu, pertimbangan lain pemilihan kombinasi emulgator ini adalah tidak adanya interaksi kimia dengan sunflower oil ${ }^{(5)}$.

Tujuan penelitian ini adalah untuk menghasilkan suatu kombinasi emulgator Tween 80 dan Span 80 yang dapat menghasilkan formula sediaan krim sunflower oil yang memenuhi persyaratan kualitas, ditinjau dari sifat fisik dan stabilitas fisik sediaan. Sifat fisik yang diuji meliputi viskositas dan daya sebar, sedangkan stabilitas fisik ditinjau dari pergeseran viskositas. Metode optimasi yang digunakan adalah simplex lattice design, dengan metode ini menentukan formula optimal dari campuran bahan, dalam desainnya jumlah total bagian komponen campuran dibuat tetap ${ }^{(6)}$.

\section{BAHAN DAN METODE}

BAHAN. Sunflower oil (kualitas farmasetis) diperoleh dari PT. Eteris Nusantara, white petrolatum (kualitas farmasetis), white bess wax (kualitas farmasetis), asam stearat (kualitas farmasetis), metil paraben (kualitas farmasetis), propilen glikol (kualitas farmasetis), Tween 80 (kualitas farmasetis), Span 80 (kualitas farmasetis), dan aqua destilata.

METODE. Pembuatan Krim Sunflower Oil. Formula sediaan krim sunflower oil tercantum dalam Tabel 1. Diawali dengan pembuatan fase minyak dan fase air secara terpisah. Fase minyak terdiri dari vaselin putih, cera alba, dan asam stearat, dilelehkan pada suhu $65-70{ }^{\circ} \mathrm{C}$, kemudian ditambahkan Span 80 dan sunflower oil pada suhu yang sama sambil diaduk sampai homogen. Fase air terdiri dari propilen glikol, metil paraben, dan Tween 80, dicampur dan dipanaskan pada suhu $65-70{ }^{\circ} \mathrm{C}$. Fase minyak dicampurkan dengan fase air menggunakan mixer dengan kecepatan $600 \mathrm{rpm}$. Setelah semuanya

Tabel 1. Formula sediaan krim sunflower oil.

\begin{tabular}{|c|c|c|c|c|c|}
\hline \multirow{2}{*}{ Bahan (\%) } & \multicolumn{5}{|c|}{ Formula } \\
\hline & 1 & 2 & 3 & 4 & 5 \\
\hline Sunflower oil & 5 & 5 & 5 & 5 & 5 \\
\hline Vaselin putih & 52 & 52 & 52 & 52 & 52 \\
\hline Cera Alba & 3 & 3 & 3 & 3 & 3 \\
\hline Span 80 & 6 & 5 & 4 & 3 & 2 \\
\hline Metil paraben & 0,5 & 0,5 & 0,5 & 0,5 & 0,5 \\
\hline Propilen glikol & 30 & 30 & 30 & 30 & 30 \\
\hline Aqua destilata & ad 100 & ad 100 & ad 100 & ad 100 & ad 100 \\
\hline
\end{tabular}


tercampur ditambahkan aqua destilata dan diaduk selama 8 menit sambil didinginkan.

Pengujian Daya Sebar Krim Sunflower Oil. Ditimbang 1 gram krim sunflower oil, diletakkan tepat di tengah kaca bulat berskala. Kaca bulat tanpa skala serta pemberat $125 \mathrm{~g}$ diletakkan di atasnya dan dibiarkan secara 1 menit, kemudian dicatat diameter penyebarannya. Pengujian daya sebar dilakukan dalam rentang waktu 24-48 jam setelah krim sunflower oil selesai dibuat dan setelah penyimpanan selama satu bulan.

Pengujian Pergeseran Viskositas Krim Sunflower Oil. Dilakukan pengukuran viskositas setelah sediaan krim disimpan selama satu bulan pada suhu kamar.

Pengujian Transepidermal Water Loss (TEWL). Enam volunteer yang sehat (3 laki-laki dan 3 perempuan) dengan rentang usia 18 sampai 25 tahun yang telah menandatangani informed consent dipersiapkan dengan cara tidak memakai produk skin care apapun selama 24 jam dan selama 4 jam tidak mandi sebelum eksperimen dimulai. Pre-treatment dilakukan dengan membasuh lengan volunteer dengan air hangat, dikeringkan dengan hati-hati dan dibiarkan 30 menit. Setelah itu, area kulit pada lengan atas dalam diukur kadar air dalam kulit sebelum dioleskan krim.

Oleskan krim sunflower oil dalam area yang telah diukur kadar airnya dan dibiarkan selama 30 menit, setelah itu diukur kembali dengan tewameter. Hasil pengukuran kemudian dihitung nilai rata-ratanya pada tiap kelompok berdasarkan jenis kelamin. Nilai rata-rata kemudian dibandingkan antara sebelum pemakaian dan sesudah pemakaian produk. Apabila penurunan nilai rata-rata TEWL antara sebelum dan sesudah treatment $\geq 8 \%$, maka ada perbedaan nilai moisturizer kulit karena perlakuan sediaan yang artinya sediaan mampu meningkatkan kelembapan kulit $^{(7)}$.

Analisis Hasil. Hasil perolehan respon dilakukan pendekatan dengan persamaan simplex lattice design yaitu $\mathrm{Y}=\mathrm{a}(\mathrm{X} 1)+\mathrm{b}(\mathrm{X} 2)+\mathrm{ab}(\mathrm{X} 1)(\mathrm{X} 2)$. Persamaan simplex selanjutnya divalidasi dengan cara menghitung perolehan regresi dari persamaan yang telah diperoleh menggunakan metode statistik F hitung dengan taraf kepercayaan 95\%. Formula dengan komposisi campuran optimum diuji efikasinya secara in vivo pada kulit volunteers dengan uji TEWL menggunakan alat tewameter ${ }^{\mathbb{B}}$ TM-300. Perolehan nilai TEWL sebelum dan sesudah treatment dihitung nilai rata-ratanya dalam tiap kelompok kemudian dibandingkan. Bila peningkatan kelembapan pada kulit setelah pemberian krim sunflower oil $\geq 8 \%$ artinya krim sunflower oil dapat memberikan efek moisturizer.

\section{HASIL DAN PEMBAHASAN}

Hasil Pembuatan Krim Sunflower Oil. Pembuatan formula dimodifikasi dari formula acuan ${ }^{(8)}$ seperti yang tertera pada Tabel 1. Hasil uji organoleptis, kelima formula berwarna putih dan memiliki bau khas. Hasil uji tipe krim dengan miscibility test, kelima formula larut dalam air. Kelima formula memiliki pH 5, ketika diuji dengan menggunakan kertas $\mathrm{pH}$ universal.

Hasil Pengujian Viskositas Krim Sunflower Oil. Tabel 2 menunjukkan data viskositas dan daya sebar sediaan krim sunflower oil yang diperoleh 24-48 jam setelah pembuatan. Viskositas merupakan tahanan suatu cairan untuk mengalir, dimana semakin tinggi nilai viskositas maka semakin besar ketahanan cairan untuk mengalir ${ }^{(9)}$.

Dalam penelitian ini, kriteria viskositas sediaan semisolid yang diterima adalah 50 sampai 200 d.Pa. ${ }^{(10)}$. Berdasarkan data yang diperoleh, pengaruh Span 80 lebih besar terhadap peningkatan respon viskositas dibandingkan Tween 80 . Data menunjukkan bahwa semakin tinggi proporsi Span 80 dalam sistem emulgator, respon viskositas cenderung meningkat. Ketika proporsi Span 80 semakin tinggi, maka droplet fase minyak akan semakin stabil, dan kemungkinan terjadinya penggabungan antar droplet dapat diminimalkan. Droplat yang stabil dalam emulsi akan berpengaruh terhadap peningkatan viskositas sediaan krim.

Hasil Pengujian Daya Sebar Krim Sunflower Oil. Uji daya sebar dilakukan untuk memberikan gambaran mengenai kemampuan pemerataan dan penyebaran krim sunflower oil saat dioleskan pada kulit. Semakin besar nilai daya sebar maka sediaan makin mudah diaplikasikan ke kulit, sehingga lebih banyak luas permukaan yang kontak dengan kulit. Nilai daya sebar krim sunflower oil yang diinginkan adalah 5-7 cm karena termasuk dalam sediaan semifluid $^{(11)}$. Pemilihan kategori semifluid bertujuan

$\begin{array}{lccccc} & \text { Formula } 1 & \text { Formula } 2 & \text { Formula } 3 & \text { Formula } 4 & \text { Formula } 5 \\ \text { Viskositas }(\mathrm{dPas}) & 160 \pm 0 & 160 \pm 0 & 153,33 \pm 5,77 & 153,33 \pm 5,77 & 143,33 \pm 5,77 \\ \text { Daya sebar }(\mathrm{cm}) & 4,23 \pm 0,25 & 4,57 \pm 0,25 & 5,03 \pm 0,06 & 5,23 \pm 0,21 & 5,33 \pm 0,06\end{array}$


Tabel 3. Data pergeseran viskositas krim sunflower oil.

\begin{tabular}{lccccc}
\hline \multicolumn{1}{c}{ Sifat fisik } & Formula 1 & Formula 2 & Formula 3 & Formula 4 & Formula 5 \\
\hline $\begin{array}{l}\text { Pergeseran } \\
\text { viskositas (\%) }\end{array}$ & $0 \pm 0$ & $4,17 \pm 3,61$ & $4,31 \pm 3,73$ & $6,53 \pm 0,24$ & $6,83 \pm 6,67$ \\
\hline
\end{tabular}

agar sediaan krim sunflower oil memiliki penyebaran yang tinggi dan mudah untuk diaplikasikan di kulit. Hasil pengamatan daya sebar krim sunflower oil pada Tabel 2 menunjukkan pada formula 3, 4, dan 5 yang memenuhi kriteria daya sebar yang diinginkan.

Hasil Pengujian Pergeseran Viskositas Krim Sunflower Oil. Pergeseran viskositas pada sediaan krim diamati setelah krim disimpan selama 30 hari pada kondisi suhu kamar. Uji ini dilakukan untuk memprediksi stabilitas sediaan krim yang dihasilkan selama masa penyimpanan. Berdasarkan data pada Tabel 3, terlihat adanya pergeseran viskositas pada setiap formula, dan pergeseran viskositas terbesar terjadi pada formula 5 . Terjadinya pergeseran viskositas ini juga diiringi dengan perubahan ukuran partikel droplet, dimana ukuran droplet menjadi lebih besar (Gambar 1).

Adanya peningkatan ukuran droplet menunjukan bahwa emulgator yang ada tidak lagi mampu menjaga stabilitas droplet yang ada, karena kohesivitas fase minyak yang lebih kuat, sehingga droplet-droplet cenderung untuk bergabung membentuk droplet yang lebih besar (koalesen). Semakin besar ukuran droplet, rigiditas dan ketahanan sistem akan semakin kecil, dan kecenderungan yang mengarah ke pemisahan fase akan semakin besar. Berdasarkan data pada Tabel 3 , pergeseran viskositas akan semakin tinggi ketika proporsi Span 80 semakin kecil dalam campuran emulgator. Hal ini menunjukkan ketika semakin kecil proporsi Span 80, maka stabilitas droplet yang terbentuk akan semakin kecil, dan kemungkinan terjadinya penggabungan droplet akan semakin besar. Ketika droplet semakin besar, terjadi pergeseran viskositas yang mengarah pada penurunan viskositas sistem.

Penetapan Formula Optimum Krim Sunflower Oil. Secara umum, kombinasi antara Tween 80 dan Span 80 sebagai emulgator akan menghasilkan sistem emulsi yang baik, dimana fungsi Tween 80 dan Span 80 akan saling melengkapi. Dalam penelitian ini, formula optimum sediaan krim sunflower oil didasarkan pada sifat fisik yang dihasilkan, meliputi viskositas dan daya sebar, serta stabilitas fisik yang diwakili oleh parameter pergeseran viskositas.

Tabel 4 menunjukkan persamaan matematika yang dihasilkan untuk masing-masing respon yang diuji. Pada respon viskositas, baik Tween 80 maupun Span 80 cenderung akan meningkatkan viskositas sediaan krim, namun koefisien Span 80 sedikit lebih besar dibandingkan Tween 80, sehingga dapat diprediksi

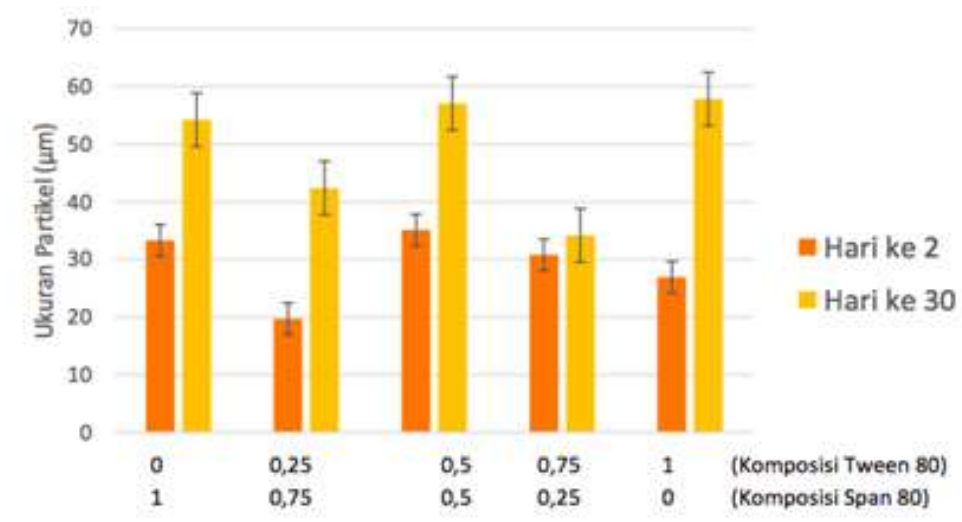

Gambar 1. Diagram komposisi emulgator vs ukuran partikel droplet krim sunflower oil.

Tabel 4. Persamaan matematis untuk masing-masing respon sediaan krim sunflower oil.

\begin{tabular}{cc}
\hline Respon & Persamaan matematika \\
\hline Viskositas & $\mathrm{Y}=143,33(\mathrm{~A})+160(\mathrm{~B})+6,67(\mathrm{~A})(\mathrm{B})$ \\
Daya sebar & $\mathrm{Y}=5,33(\mathrm{~A})+4,23(\mathrm{~B})+(\mathrm{A})(\mathrm{B})$ \\
Pergeseran viskositas & $\mathrm{Y}=6,83(\mathrm{~A})+3,57(\mathrm{~A})(\mathrm{B})$ \\
\hline
\end{tabular}

Keterangan : $\mathrm{A}=$ proporsi Tween $80, \mathrm{~B}=$ proporsi Span 80 
Tabel 5. Data pengujian TEWL

\begin{tabular}{|c|c|c|c|c|c|}
\hline \multirow{2}{*}{$\begin{array}{c}\text { No } \\
\text { responden }\end{array}$} & \multirow{2}{*}{ Jenis Kelamin } & \multicolumn{2}{|c|}{ TEWL (g/jam.m²) } & \multirow{2}{*}{$\begin{array}{c}\text { Penurunan TEWL } \\
(\%)\end{array}$} & \multirow[t]{2}{*}{ Significant $\mathrm{p}$} \\
\hline & & Sebelum & Sesudah & & \\
\hline 1 & \multirow{3}{*}{ Perempuan } & 11,81 & 9,69 & 17,95 & \multirow{3}{*}{$\mathrm{p}<0,05$} \\
\hline 2 & & 11,64 & 9,16 & 21,31 & \\
\hline 3 & & 18 & 12,92 & 28,22 & \\
\hline 4 & \multirow{3}{*}{ Laki-laki } & 18,1 & 11,04 & 39,01 & \multirow{3}{*}{$\mathrm{p}<0,05$} \\
\hline 5 & & 31,44 & 20,73 & 34,06 & \\
\hline 6 & & 20,25 & 12,54 & 38,07 & \\
\hline
\end{tabular}

bahwa Span 80 berpengaruh terhadap viskositas lebih besar dibandingkan Tween 80 . Hal ini dapat terjadi karena bagian hidrofobik dari Span 80 mampu mempertahankan stabilitas droplet fase minyak dengan baik, dimana droplet yang stabil akan meningkatkan ketahanan dari sistem emulsi dalam krim.

Untuk respon daya sebar, koefisien Tween 80 sedikit lebih besar dibandingkan Span 80 sehingga dapat diprediksi bahwa dalam formula sediaan krim ini Tween 80 berpengaruh terhadap peningkatan daya sebar sediaan krim lebih besar dibandingkan Span 80. Semakin besar daya sebar krim menunjukkan bahwa tahanan alir (viskositas) dari sediaan krim semakin kecil.

Terdapat suatu kondisi dimana droplet-droplet yang terbentuk dalam krim tidak lagi stabil, yang akan meningkatkan kecenderungan untuk bergabung dengan droplet yang lain. Dalam hal ini, dimungkinkan rantai polioksietilen Tween 80 yang mengarah ke bagian fase air tidak mampu lagi menjadi halangan sterik dan menahan desakan koalesen droplet, sehingga terjadi penurunan viskositas sistem yang mengarah pada peningkatan daya sebar. Pada respon pergeseran viskositas, koefisien Tween 80 jauh lebih besar dibanding Span 80 sehingga diprediksi Tween 80 lebih berpengaruh terhadap pergeseran viskositas dibanding Span 80.

Setelah dianalisis, ketiga persamaan Simplex Lattice Design untuk ketiga respon tersebut dinyatakan regresi, sehingga dapat dikatakan bahwa persamaan tersebut dapat digunakan untuk untuk memprediksi respon pada berbagai perbandingan komposisi Tween 80 dan Span 80.

Berdasarkan profil kurva komposisi emulgator terhadap respon yang diuji, terlihat bahwa semakin tinggi Tween 80 cenderung akan menurunkan respon viskositas, namun di sisi lain akan meningkatkan respon daya sebar dan pergeseran viskositas. Kriteria formula optimum penelitian ini adalah sediaan yang memiliki respon sifat fisik dan stabilitas fisik yang baik dengan kriteria viskositas (50-200 d.Pa.s), daya sebar $(5-7 \mathrm{~cm})$, dan pergeseran viskositas
$(<10 \%)$. Berdasarkan hasil analisis data, diperoleh area komposisi optimum antara kombinasi emulgator Tween 80 dan Span 80 yang dapat menghasilkan formula sediaan krim sunflower oil yang dapat memenuhi kriteria optimum.

Hasil Pengujian Transepidermal Water Loss (TEWL). Transdepidermal Water Lost (TEWL) adalah sebuah metode dalam dermatologi untuk memperkirakan skin barrier secara in vivo(7), dalam penelitian ini digunakan formula 3 yang memenuhi kriteria formula optimum. Berdasarkan data pada Tabel 5, ada perbedaan yang signifikan antara TEWL sebelum pemakaian krim sunflower oil dan TEWL setelah pemakaian krim sunflower oil, artinya terjadi penurunan TEWL $\geq 8 \%$ baik pada kelompok perempuan maupun laki-laki. Oleh karena itu dapat disimpulkan bahwa krim sunflower oil memiliki efek pelembap atau moisturizer.

\section{SIMPULAN}

Diperoleh suatu kombinasi emulgator Tween 80 dan Span 80, dalam penelitian ini ditunjukkan pada perbandingan $(6: 4) \%,(7: 3) \%$ dan $(8: 2) \%$ yang dapat menghasilkan formula sediaan krim sunflower oil yang memenuhi persyaratan kualitas, ditinjau dari sifat fisik dan stabilitas fisik sediaan. dan memiliki efek sebagai pelembap, dibuktikan dengan nilai TEWL $\geq 8 \%(\mathrm{p}<0,05)$.

\section{DAFTAR PUSTAKA}

1. Cooke A, Cork MJ, Victor S, Campbell M, Danby S, Chittock J, Lavender T. Olive oil, sunflower oil or no oil for baby dry skin or massage: a pilot, assessorblinded, randomized controlled trial (the oil in baby skincare [observe study]. Acta Derm Venereol. 2016. 96:323-30.

2. Eichenfield LF, McCollum A, and Msika P. The benefits of sunflower oleodistillate (SOD) in pediatric dermatology. Pediatric Dermatology. 2009. 26(6):66975

3. Rowe RC, Sheskey PJ, and Quinn ME. Handbook of 
67 HUSEIN ET AL.

pharmaceutical excipients. Pharmaceutical Press. 2009.

4. Kim, Cherng-ju. Advanced pharmaceutics: physicochemical principles. CRC Press LLC, Florida. 2005. 214-35.

5. Gupta V, Nagpal M, Aggarwal G, Kaur R, Singh S, Behl T, Jain UK. Formulation, development, and evaluation of non-ionic surfactant based organogel for transdermal delivery of acyclovir. International Journal of Innovative Pharmaceutical Sciences and Research. 2014. 2(7):1297- 310.

6. Bolton S. and Bon C. Pharmaceutical statistic practical and clinical applications, 4th ed. Marcel Dekker, Inc. New York. 2004. 523-24.

7. Patzelt A, Lademann J, Richter H, Darvin ME, Schanzer S, Thiede G. Sterry W, Vergou T, Hauser M. In vivo investigations on the penetration of various oils and their influence on the skin barrier. Skin Research and Technology. 2011.18:364-69.
8. Patel RP, and Kamani R. Formulation optimization and evaluation of mometasone furoate cream. Journal of Pharmacy Research. 2009. 2(10):1565-69.

9. Sinko JP. Martin's physical pharmacy and pharmaceutical science: physical chemical and biopharmaceutical principles in the pharmaceutical science. 6thed. Lippincott Williams \& Wilkins, Philadelphia. 2011. 767, 800, 816-18.

10. Xenograf OC, Wisudyaningsih B, Muslichah S, Hidayat MA. Formulasi dan penentuan stress testing sediaan $\mathrm{krim} \mathrm{m} / \mathrm{a}$ dan $\mathrm{a} / \mathrm{m}$ ekstrak etanol edamame (Glycine max). Jurnal Pustaka Kesehatan. 2015. 3(3):426.

11. Garg A, Aggarwal D, Garg S, and Singla AK. Spreading of semisolid formulations : an update. Pharmaceutical Technology. 2002. 84-105. 